\title{
PROJECT EVALUATION UNDER INFLATIONARY CONDITIONS
}

\author{
Halil SARIASLAN, Ph. D. \\ Professor of Business Administration \\ Faculty of Political Sciences \\ University of Ankara
}

\section{CONVENTIONAL USE OF DISCOUNTED CASH FLOW TECNIQUES IN PROJECT EVALUATION}

Although the term project has different connotations, in an economic and managerial context it generally refers to an investment proposal with implications in the future. That is, in the most common case the defining characteristic of an investment proposal is that it comprises a planned series of capital expenditures (cash outflows) undertaken in anticipation of their generating a larger series of cash inflows at various times in the future. As such, the main purpose of project evaluation or investment appraisal procedure is simply the comparison of uncertain future cash inflows with cash outflows which might also be uncertain. The basic techniques used by economists and financial analysts for this comparison purpose are most often internal rate of return and net present value techniques. This practice has been so generally accepted that the whole procedure of evaluating the profitability of an investment based on the concept of discounting is often referred to as the discounted cash flow techniques.

To illustrate the conventional use of these techniques; consider an investment proposal costing $\$ 80.000$, that depreciation is straight line, corporate tax rate is $50 \%$, and that the following cash inflows are expected.

TABLE 1

Cash

$\begin{array}{lll}\text { Year } & & \text { Inflows } \\ 1 & & 60,000 \\ 2 & & 60,000 \\ 3 & & 60,000 \\ 4 & & 60,000\end{array}$

\begin{tabular}{c} 
Depreciation \\
\hline 20,600 \\
20,000 \\
20,000 \\
20,000
\end{tabular}

Taxes

20,000

20,000

20,000

20,000
Cash Inflows

After Tax

40,000

40,000

40,000

40,000 
Depreciation is subtracted from cash inflows to find taxable income, on which a $50 \%$ tax rate is applied, as shown in column three of the table.

Further assuming that the cost of capital or discount factor is 30 percent, the net present value of this investment proposoal can be computed by the following formula as given below.

$$
N P V=\sum_{t=0}^{n} \frac{\left(I_{t}-O_{t}\right)}{(1+k)^{t}}
$$

or,

$$
\mathrm{NPV}=\sum_{\mathrm{t}=1}^{\mathrm{n}}-\frac{\left(\mathrm{I}_{\mathrm{t}}-\mathrm{O}_{\mathrm{t}}\right)}{(1+\mathrm{k})^{\mathrm{t}}}--\mathrm{C}_{0}
$$

$\mathrm{NPV}=$ the net present value of the investment propasal.

$\mathrm{n}$ = final period or the economic life of the investment during which cash flows are expected.

$I_{t}=$ cash inflows after tax in time period $t$.

$\mathrm{O}_{\mathrm{t}} \quad=$ cash outflows in time period $t$.

$\mathrm{k} \quad=$ cost of capital or discount rate.

$\mathrm{C}_{\mathrm{o}}=$ cost of project at time $\mathrm{o}$.

Accordingly, the net present value of the investment proposal is:

$$
\begin{aligned}
& N P V=\frac{(O-80.000)}{(1+0.30)^{\circ}}+\frac{(40.000-0)}{(1+0.30)^{1}}+\frac{(40.000-0)}{(1+0.30)^{2}}+\frac{(40.000-0)}{(1+0.30)^{3}}+\frac{(40.000-0)}{(1+0.30)^{4}} \\
& N P V=-80,000+30,769.2+23,668.6+18,206.6+14,005.1 \\
& N P V=6,649.5 \text { dollars. }
\end{aligned}
$$

Therefore, since the investment proposal generates a positive net prevent value of $\$ 6,649,5$, the proposal is accepted. That is, it is a profitable business.

Additionally, if desired, one may calculate the internal rate of return on the investment proposal by finding the discount rate which equates the net present value to zero. That is, through the formula,

$$
\sum_{t=0}^{n} \frac{\left(I_{t}-O_{t}\right)}{(1+k)^{t}}=0
$$

or, 


$$
\sum_{t=0}^{n} \frac{I_{t}}{(1+k)^{t}}=\sum_{t=0}^{n} \frac{O_{t}}{(1+k)^{t}}
$$

the discount rate $\mathrm{k}$ can be calculated by the trial and error method as follows.

$$
\frac{-80.000}{(1+k)^{0}}+\frac{40.000}{(1+k)^{1}}+\frac{40.000}{(1+k)^{2}}+\frac{40.000}{(1+k)^{3}}+\frac{40.000}{(1+k)^{4}}=0
$$

The discount rate or the internal rate of return which equates the present value of cash inflows to the cost of investment proposal is around 35 percent. If this rate is equal to or greater than the hurdle or cut-off rate which is usually based on current capital cost or the required rate of return as perceived by investors or creditors, then the investment proposal is accepted.

In spite of the fact that the above given example is simplified for the sake of explaining the cash flow techniques, it does, however, reflect the essential conventional use of the techniques and the assumption behind them. Such general practice of the cash flow techniques can be criticized in many ways. For the purpose of this paper, one inherent weakness of the cash flow techniques, which makes them inappropriate for evaluating investment projects whose payoffs will come years down the road, is that they ignore how inflation will effect the various cash flows in the future as explained in the following section.

\section{BIASES IN CONVENTIONAL DISCOUNTED CASH FLOW TECHNIQUES UNDER INFLATION}

Inflation is a fact of economic life in almost all countries and seems to be an epidemic disease of Western economies. It may be considered as a special project risk of changing prices to which investment projects are exposed. The presence of inflation in an economy distorts project selection devision through the discounted cash flow techniques in many ways as follows.

1. One principal reason is that as income grows with inflation, an increasing portion is taxed since depreciation charges are based on original rather than replacement costs. Therefore, the real cash'inflows do not keep up with inflation. ' To explain this point, let us refer back to the

1 Van Horne, James C. Financial Management and Policy, (London: Prentice-Hall International, Inc., 1980), p. 130. 
example given in the preceding pages, where the net present value of the investment proposal was $\$ 6,649.5$ under the assumption that no inflation is expected.

Now, suppose that the inflation rate per year is 20 percent and that cash inflows are expected to grow at this inflation rate over the useful life of the proposed investment project. That is to say, the cash inflows without inflation presented in Table 1 will be increased by the factor. $(1+0.20)^{\mathrm{n}}$. For example, the cash inflow of $\$ 60,000$ in the forth year in the Table 1 will amount to:

$60.000(1+0.20)^{4}=124,416$ dollars.

as given below.

TABLE 2

\begin{tabular}{|c|c|c|cc|}
\hline Year & $\begin{array}{c}\text { Adjusted } \\
\text { Cash Inflows }\end{array}$ & Depreciation & & $\begin{array}{c}\text { Adjusted } \\
\text { Cash Inflows } \\
\text { After Tax (AI }\end{array}$ \\
\hline 1 & 72.000 & 20.000 & 26.000 & 46.000 \\
2 & 86.400 & 20.000 & 33.200 & 53.200 \\
3 & 103.680 & 20.000 & 41.840 & 61.840 \\
4 & 124.416 & 20.000 & 52.208 & 72.208 \\
\hline
\end{tabular}

As seen, the cash inflows after tax are more than those before inflation. However, if one is concerned with the real as opposed to the nominal value of these cash inflows, they must be deflated by the inflation rate anticipated. That is, cash inflows after tax must be divided by the factor $(1+0.20)^{\mathrm{n}}$ to obtain real cash inflows after tax. Thus, the last column of the Table 2 reduces to:

\begin{tabular}{cc}
\hline Year & $\begin{array}{c}\text { Real Cash Inflows } \\
\text { After Tax }\left(\mathbf{R I}_{\mathbf{t}}\right)\end{array}$ \\
\hline 1 & 38.333 \\
2 & 36.944 \\
3 & 35.787 \\
4 & 34.823 \\
\hline
\end{tabular}

Needless to say that real cash inflows after tax are less than the nominal cash inflows in Table 1 and decline over time. The net present value in this case can be calculated by the previously given formula: 
$\mathrm{NPV}=\sum_{\mathrm{t}=0}^{n} \frac{\left(\mathrm{RI}_{\mathrm{t}}-\mathrm{RO}_{\mathrm{t}}\right)}{(1+\mathrm{k})^{\mathrm{t}}}$

or,

$\mathrm{NPV}=\sum_{\mathrm{t}=0}^{\mathrm{n}} \frac{\left(\mathrm{AI}_{\mathrm{z}}-\mathrm{AO}_{\mathrm{t}}\right)}{(1+\mathrm{k})^{\mathrm{t}}(1+\mathrm{d})^{\mathrm{t}}}$

Where:

$R I_{t}=$ real cash inflows after tax in time period $t$

$\mathrm{RO}_{\mathrm{t}}=$ real cash outlows in time period $\mathrm{t}$

$\mathrm{AI}_{\mathrm{t}}=$ inflation adjusted cash inflows after tax in time period $\mathbf{t}$

$\mathrm{AO}_{\mathrm{t}}=$ inflation adjusted cash outflows after tax in time period $t$

$\mathrm{k}=$ cost os capital or discount rate

$\mathrm{d}=$ inflation rate.

Thus, the net present value of our sample project based on real cash inflows after tax, then, is:

$$
\begin{aligned}
\mathrm{NPV} & =\frac{(0-80,000)}{(1+0,30)^{0}}+\frac{(38,333-0)}{(1+0,30)^{1}}+\frac{(36,944-0)}{(1+0,30)^{2}} \\
& +\frac{(35,787-0)}{(1+0,30)^{3}}+\frac{(34,823-0)}{(1+0,30)^{4}}
\end{aligned}
$$

or, based on cash inflows with inflation after tax,

$$
\begin{aligned}
\text { NPV } & =\frac{(0-80,000)}{(1+0,30)^{0}(1+0,20)^{0}}+\frac{(46,000-0)}{(1+0,30)^{1}(1+0,20)^{1}} \\
& +\frac{(53,200-)}{(1+0,30)^{2}(1+0,20)^{2}}+\frac{(61,840-0)}{(1+0,30)^{3}(1+0,20)^{3}} \\
& +\frac{(72,208-0)}{(1+0,30)^{4}(1+0,20)^{4}} \\
N P V & =-171
\end{aligned}
$$

in contrast to the previous $6,649,5$ dollars without inflation.

Consequently, under this inflation condition the same investment proposal, this time, should be rejected because it gives rise to a loss. The 
reason as indicated before, is that depreciation charges do not keep up with inflation and that an increasing portion of the tax savings is subjected to taxation. Accordingly, under inflationary conditions there would be less incentive for compaines to invest in capital intensive projects with pay off years down the road, since most equity investors expect that firms will maintain the rate of return on equity capital during periods of general inflation at a level which adequately compensate in real terms for the opportunities foregone. Based on this premise, it can be stated that during periods of high inflation there would be an incentive for companies to seek investment areas with shorter life periods that would result in myopic investment decisions in many businesses. This, in turn, would lead to a less capital intensive industry in the economic system. ${ }^{2}$

In summary, companies should take expected inflation into account in estimating cash flows associated with an investment project. However, often they do not follow the procedure just set forth with the assumption that cash inflows and outflows will rise at the same rate during inflationary periods. If this assumption holds, then there is not need to increase cash flows in the future time by the inflation factor $(1+d)^{n}$ and later to deflate or reduce them by the same factor $(1+d)^{n}$, as indicated below,

$$
N P V=\sum_{t=0}^{n} \frac{\left(I_{t}-O_{t}\right)(1+d)^{t}}{(1+k)^{t}\left(1+\alpha^{t}\right)^{t}}
$$

Since the $(1+d)^{t}$ terms in the numerator and denominator cancel each other, we are left with the same formula in the absence of inflation,

$$
\mathrm{NPV}=\sum_{\mathrm{t}=0}^{\mathrm{n}} \frac{\left(\mathrm{I}_{\mathrm{t}}-\mathrm{O}_{\mathrm{t}}\right)}{(1+\mathrm{k})^{\mathrm{t}}}
$$

Nevertheless, it should be kept in mind that this assumption will not hold for many reasons. First, future inflation does not affect depreciation charges on existing assets because when the asset is acquired these charges are known with certainty. Thus, an increasing portion of the tax savings is subjected to taxation, as explained in the preceding pages. ${ }^{3}$ Secondly, inlationary increases in cash inflows and outlows will vary depending on the nature of projects. For instance, in projects involving sales or procurement of raw materials at a contractual price agreed some years in advance the effect of inflation depends on the particular condi-

\footnotetext{
${ }^{2}$ For further discussion of this point, see Charles Nelson, "Inflation and Capital Budgeting", Journal of Finance, 31 (June 1976), pp. 923-931.

${ }^{3 .}$ For the tax effect of inflation, see Hai Hong, "Inflation and the market value of the Firm:. Theory and Tests" Journal of Finance, 32 (Sept. 1977) 131-148.
} 
tions or provisions for price escalation in the contract. Even in some cases the elements constituting cash flows will vary significantly through price increases. For example, labor costs may increase more than costs of raw materials or vice versa, when cash outflow estimates are concerned. In any case, it is of vital importance that inflation which is the fact of economic life be embodied in the cash flow estimates through a procedure such as the one that will be explained in the last section of this paper. Otherwise, project evaluation or investment appraisal will result in a bias of the type described so far.

2. A second bias in using discounted cash flow techniques when companies assume that cash flows will not change throughout the life of the project is that related to discount factor. As a general practice, companies estimate future cash flows on the basis of existing prices. However, when the cash flows are discounted, the current capital cost, which usually embodies a premium for expected inflation, is used." In general, a typical current discount rate $(\mathrm{k})$ used in the discounted cash flow techniques may be viewed as composed of there parts: namely, a risk-free time value of money $\left(k_{f}\right)$, a risk premium $\left(k_{r}\right)$ that increases with project risk, and a premium for expected inflation (d), as presented below: ${ }^{5}$

$$
1+\mathrm{k}=\left(1+\mathrm{k}_{\mathrm{f}}\right)\left(1+\mathrm{k}_{\mathrm{r}}\right)(1+\mathrm{d})
$$

Nonetheless, for the purpose of this paper if we combine $\left(1+k_{f}\right)$ and $\left(1+k_{r}\right)$ discount factors and set

$$
\left(1+k_{\mathrm{f}}\right)\left(1+k_{\mathrm{r}}\right)=(1+\mathrm{r})
$$

as the discount factor representing the real cost of capital, then

$$
\begin{aligned}
1+\mathrm{k} & =(1+\mathrm{r})(1+\mathrm{d}) \\
\mathrm{k} & =(1+\mathrm{r})(1+\mathrm{d})-1 \\
\mathrm{k} & =\mathrm{r}+\mathrm{d}+\mathrm{rd}
\end{aligned}
$$

For example, a $10 \%$ real cost of capital with a $20 \%$ expected inflation rate would imply a discount factor of

$$
\begin{aligned}
1+k & =(1+0.10)(1+0.20) \\
1+k & =1+0,20+0,10+0,02 \\
k & =0.32
\end{aligned}
$$

4 Van Horne, James C., "A Note on Biases in Capital Budgeting Introduced by Inflation", Journal of Financial and Quantitative Analysis, 6 (January 1971). pp. 653-658.

"Hodder, James E. and Riggs, Henry E., "Pitfalls in Evaluating Risky Projects", Harvard Business Review, 1 (Jan.-Feb. 1885), pp. 131. 
or a nominal discount rate of exactly 32 percent. Moreover, Irving Fisher expressed the nominal rate of interest on a financial instrument as the sum of the real rate and the rate of price change expected over the life of the instrument. This observed phenomenon, which is known as the "Fisher effect", implies that the required rate of return from a project in nominal terms is the sum of the real rate of return and the weighted average rate of inflation expected throughout the life of the project. ${ }^{6}$

Consequently, if expected inflation is embodied. in the discount factor: then the calculated worth of the net present value will be downward biased since the denominator reflects inflation but the numerator does not, and this produces bias in the conventional use of discounted cash flow techniques.

To illustrate this point, consider a project that costs $\$ 45,000$ at present (time 0 ) and its expected cash flows as given below; and further assume straight line depreciation, a corporate tax rate of $50 \%$, and a discount rate or a required rate of return of $30 \%$.

TABLE 3

\begin{tabular}{|c|c|c|c|c|}
\hline Year & $\begin{array}{l}\text { Cash } \\
\text { Inflows }\end{array}$ & Depreciation & Taxes & $\begin{array}{l}\text { Cash Inflows } \\
\text { After Tax (It) }\end{array}$ \\
\hline 1 & 30,000 & 15,000 & 7,500 & 22,500 \\
\hline 2 & 30,000 & 15,000 & 7,500 & 22,500 \\
\hline 3 & 30,000 & 15,000 & 7,500 & 22,500 \\
\hline
\end{tabular}

The net present value through the formula:

$\mathrm{NPV}=\sum_{\mathrm{t}=0}^{\mathrm{n}} \frac{\left(\mathrm{I}_{\mathrm{t}}-\mathrm{O}_{t}\right)}{(1+\mathrm{k})^{\mathrm{t}}}$

is -4137 dollars. For the result is negative the project proposal must be rejected.

However, as explained earlier, this decision is biased in that the discount factor embodies a part reflecting the expected future inflation, while the cash inflows do not. To remove this bias, the cash inflows have to be adjusted for the expected inflation properly. Now, assume that the present rate of inflation is $15 \%$ and that it will prevail over the three year life of the project. If the cash inflows will increase by the rate of

- Van Horno. James E., Financial Managament ... p. 132. 
inflation, they must be multiplied by the factor $(1+0.15)^{t}$, as presented below. For example, the cash inflow in year 2 will amount to

$30,000(1+0.15)^{2}=39,675$ dollars.

TABLE 4

\begin{tabular}{ccccc}
\hline Year & $\begin{array}{l}\text { Cash } \\
\text { Inflows }\end{array}$ & Depreciation & Taxes & $\begin{array}{c}\text { Cash Inflows } \\
\text { After Tax (It) }\end{array}$ \\
\hline 1 & 34,500 & 15,000 & 9,750 & 24,750 \\
2 & 39,675 & 15,000 & 12,338 & 27,337 \\
3 & 45,626 & 15,000 & 15,313 & 30,313 \\
\hline
\end{tabular}

In this case: based on the last column of the Table 4, total cost of $\$ 45,000$ and $30 \%$ required rate of return or discount rate, the net present value is 4012 dollars. Therefore, since the result is positive, the project proposal that was rejected before, this time, should be accepted. This, in turn, indicates the importance of taking into account the rate of inflation expected explicitly when companies are estimating future cash flows. Various methodologies for this purpose are to be presented in the next section:

\section{INFLATION ADJUSTMENT IN DISCOUNTED CASH FLOW TECHNIQUES}

Notwithstanding the fact that the conventional use of discounted cash flow techniques has been widespread, financial and project analysts habe been aware of the impact of inflation on project evaluation for the last decade. As such, there have been developed several procedures to correctly allow for inflation in discounted cash flow techniques.

1. Some analysts include inflation in the cash flows at the rates spplicable to each of its components and then use nominal (current) discount rates, which incorporate a risk- free time value of money, a risk premium, and a premium for anticipated inflation. ${ }^{7}$ Additionally, if inflation rates are expected to vary, different nominal discount rates are used to adjust the denominator for varying inflation rates. However, such a methodology will entail cumbersome calculations. For this reason, it

7 Van Horne, James C., Financial Management ... pp. 133-134.

Brigham, Eugene F., Fundamentals of Financial Management, Third Edition, (New York: The Dryden Press, 1983), pp. 313-314. 
ends up with using a single average inflation rate applicable to each segment of cash flows and a single nominal discount rate, but this is not actually correct even though it will not seriously distort the calculations. For instance, Van Horne suggests the following formula for inflation adjustment. $^{8}$

$$
N P V=\sum_{i=1}^{n} \frac{\left[I_{t}(1+\alpha d)^{t}-O_{t}(1+\beta d)^{t}\right][1-T]+F_{t} T}{(1+k)^{t}}-C_{0}
$$

where:

$\mathrm{NPV}=$ the net present value of the project at time 0

$\mathrm{n} \quad$ = final period which cash flows are expected

$\mathrm{I}_{\mathrm{t}}=$ expected value of cash inflow in period $\mathrm{t}$ in the absence of future inflation

$\mathrm{d} \quad=$ anticipated rate of inflation as denoted by expected annual rate of change in the price index.

$\alpha \quad=$ portion of $\mathrm{d}$ applicable to cash inflows

$\mathrm{O}_{\mathbf{t}}=$ expected value of cash outflows in period $\mathrm{t}$ in the absence of future inflation

$\beta \quad=$ portion of $\mathrm{d}$ applicable to cash outflows

$\mathrm{T}=$ corporate tax rate

$F_{\mathrm{t}}=$ depreciation charges on the assets in period $t$

$\mathrm{C}_{\mathrm{o}}=$ cost of project at time 0 , which is assumed to be known with certainty

$\mathrm{k} \quad=$ the nominal (current) cost of capital or discount rate which embodies the risk-free time value of money, a risk premium, and a premium for expected inflation.

In the above given formula annual depreciation in year $t$ is multiplied by the tax rate to compute tax-shield cash savings $\left(F_{t} T\right)$, where it is appropriately assumed that no increase from inflation is applicable: In fact, depreciation associated with a project increases at a very low rate, if not at all.

2. Although the methodology described above is more commonly used by analysts when adjusting for inflation, a preferable methodology is to use deflated cash flows with real discount rates. This methodology requires the project analysts estimate the cash flow in each time period,

Ibid. 
including the increase from the expected inflation attributable to each element of cash flows (for example, a zero rate for depreciation tax-shield cash savings), and then deflate the cash flows to obtain their present values through using the appropriate projected inflation for each time period..$^{9}$ Needless to say that if cash flows are expected to adjust fully with inflation, the deflation adjustment will exactly cancel the included inflation: Otherwise, depending on the rate of inflation applicable to each cash flow element, the deflated real value of future cash flows will be altered. Later on the deflated real cash flow in each time period is discounted by real discount rates which do not include a premium for inflation. Therefore, since the real discount rates appear to be more stable than the nominal discount rates, this methodology is superior to using a single nominal discount rate. ${ }^{10}$

At this point, it should be added that the real discount rate embodies the risk-free time value of money and a premium for risk. If risk associated with a project varies during project development stages as in the case of research and development projects, project analysts should exercise judgement regarding the risks attributable to each stage of project development and include it in the cash flow analysis in order not to underestimate the present value of the project. An appropriate approach would be risk adjustment using certainty equivalent values of cash flows in each development stage of the project and then discount certainty equivalent values of cash flows to the present using a single risk-free real discount rate which would just indicate the risk-free time value of money. ${ }^{11}$

Now, assuming that the risk associated with a project does not change significantly throughout the development stages of the project the methodology described above can be formulated by using the symbols defined in the first methodology explained earlier.

$$
\mathrm{NPV}=\sum_{\mathrm{t}=1}^{\mathrm{n}} \frac{\left\{\left[\mathrm{I}_{\mathrm{t}}(1+\alpha \mathrm{d})^{\mathrm{t}}-\mathrm{O}_{\mathrm{t}}(1+\beta \mathrm{d})^{\mathrm{t}}\right][1-\mathrm{T}]+\mathrm{F}_{\mathrm{t}} \mathrm{T}\right\} /(1+\mathrm{d})^{\mathrm{t}}}{(1+\mathrm{r})^{\mathrm{t}}}
$$

Where, in this case, $r$ is the real discount rate which embodies the risk-free time value of money and a risk premium, but no inflation. All the other symbols are as defined before. Additionally, if it is assumed that the expected inflation rate will change during the life cycle of the project, then different inflation rates can be included in the above given formula by adding a time subscript $t$ to $d$ as in $d_{t}$.

Hodder, James E. and Riggs, Henry E., "Pitfalls in Evaluating ...". p. 134.

10 Ibid.

11 Ibid, p. 133. 
Finally, one further point that need to be clarified here is that although our explanations given hitherto are based on the net present value method of the discounted cash flow techniques, the same reasoning would easily apply to the other methods as well. For example in evaluating investment projects through the internal rate of return method the following procedures can be followed.

a) If inflation adjusted cash flows are not deflated by the expected rate of inflation, the calculated internal rate of return should be compared with the nominal (current) cut-off or hurdle rates.

b) However, if future cash flows adjusted for inflation are deflated, then the internal rate of return that is computed on the deflated (real) cash flows should be compared with the real hurdle rates to appraise the worth of a project.

\section{BIBLOGRAPHY}

1. Brigham, Eugene F., Fundamentals, of Financial Management, Third Edition, New York: The Dryden Press, 1883.

2. Hodder, James E. and Riggs Henry E., "Pitfalls in Evaluating Risky Projects", Harvard Business Review 1 (Jan.-Feb. 1985), pp. 128-135.

3. Hong, Hai., "Inflation and the market Value of the Firm: Theory and Tests", Journal of Finance. 32 (September 1977), pp. 131-148.

4. Nelson, Charles., "Inflation and Capital Budgeting", Journal of Finance, 31 (June 1976), pp. 823-931.

5. Van Horne, James C., Financial Management and Policy, London: Prentice-Hall International Inc., 1980.

6. Van Horne, James C., "A Note on Biases in Capital Budgeting Introduced by Inflation", Journal of Financial and Quantitative Analysis, 6 (January 1971), pp. 653-658. 